\title{
Surfactant abnormality and the sudden infant death syndrome-a primary or secondary phenomenon?
}

\author{
D James, P J Berry, P Fleming, M Hathaway
}

\begin{abstract}
A prospective study of $\mathbf{4 6}$ infant deaths occurring between 3 and 100 weeks of age was performed and comprised a structured necropsy followed by collection of lung washings for surfactant phospholipid analysis and samples for microbiological examination. Of the 46 infants studied, 23 died from sudden infant death syndrome (SIDS) alone; SIDS was the cause of death in a further 12 but there were additional clinical or pathological findings insufficient in themselves to account for the death ('SIDS-plus'). In 11 there were other causes of death ('non-SIDS').

The lung washings from infants dying from SIDS had significantly lower concentrations of phosphatidylcholine and a significantly lower palmitate content in the phosphatidylcholine. There was no association between surfactant phospholipid abnormality and the presence of recognised pathogens, histological evidence of pulmonary inflammation, aspiration of stomach contents, age at death, sex, and death-postmortem interval. There were, however, lower concentrations of phosphatidylcholine and phosphatidylcholine palmitate content in infants colonised by organisms with reported phospholipase A2 activity.
\end{abstract}

Approximately 1500 babies die annually with the sudden infant death syndrome (SIDS) in England and Wales. There is no indication that this incidence is falling, and it may be rising. It is the most common cause of death in childhood after the first week of life, yet its cause or causes remain uncertain. Over the past decade many new hypotheses have been postulated to explain SIDS. ${ }^{1}$

One of the theories put forward is that surfactant deficiency or abnormality is involved. This followed the initial chance observation that lung washings from babies dying from SIDS had surfactant phospholipid abnormalities similar to those found in lung washings from babies dying from respiratory distress syndrome (or hyaline membrane disease)-the classical 'surfactant deficiency disease'. ${ }^{2}$ This finding of surfactant abnormality in lung washings from infants dying from SIDS has now been confirmed by other studies. ${ }^{3-5}$ The biochemical abnormalities in these studies, however, were not consistent. Furthermore, they were not identical to those found in respiratory distress syndrome, a condition due to primary surfactant abnormality. Finally, pressure volume studies carried out after death on lungs from babies dying from SIDS are not different from results in lungs from babies dying from non-respiratory causes. ${ }^{6}$ Are the surfactant abnormalities found in association with SIDS a primary or secondary phenomenon?

The aims of the present prospective study were, firstly, to investigate the association of surfactant phospholipid abnormality and SIDS and, secondly, to examine whether it could be a secondary phenomenon.

\section{Patients and methods}

PATIENTS

During 1986 and 1987, 46 babies dying from a variety of causes between 3 and 100 weeks of age had a detailed, structured postmortem examination performed (by PJB) between five and 76 hours after death.

The postmortem examination was carried out in accordance with a strictly defined protocol. Microbiological specimens were taken as follows: samples of blood, cerebrospinal fluid, a tracheal swab, and lung were collected using a sterile technique and submitted for bacteriological culture; nasopharyngeal aspirate, lung and faeces were submitted for virological studies. Lung samples were collected immediately after opening the chest by placing a ligature around the lingula of the left lung and removing a portion distal to the tie with a sterile scalpel blade. After inspection of the thoracic contents the lungs were separated from the trachea and mediastinal structures and weighed. Lung lavage was performed by gently flushing the lungs with normal saline $(10 \mathrm{mg} / \mathrm{kg}$ body weight) using a syringe and cannula tied into each main bronchus in turn. The samples from each lung were stored separately at $-20^{\circ} \mathrm{C}$ until required for surfactant analysis (see below). A full necropsy was carried out with particular attention to the histology of the lungs and upper respiratory tract.

After the postmortem examination, a final clinicopathological assessment of the cause of death was made in each case (by PF and PJB) on the basis of the clinical features and pathological findings and without knowledge of the biochemical results. Accordingly, the infants were classified into one of three clinicopathological groups: (1) SIDS-defined as unexpected death with no explanation as to the cause. (2) SIDS with potentially contributory associated findings (SIDS plus) - defined as unexpected death with clinical and/or postmortem abnormalities which may have signified morbidity, but which were insufficient in themselves to explain the death. (3) Non-SIDS - defined as death with clinical and postmortem features sufficient to 
provide a full and sufficient explanation of the death.

\section{SURFACTANT ANALYSIS}

The lung lavages samples (stored at $-20^{\circ} \mathrm{C}$ ) were allowed to thaw at room temperature. An aliquot of $1 \mathrm{ml}$ of lung lavage was routinely used for surfactant phospholipid analysis. A standard lipid extraction with chloroform and methanol was performed. ${ }^{7}$ The extract was then halved and both halves were subjected to two dimensional thin layer chromatography. The first half of the extract was used for quantitative assay of eight phospholipids by conversion to inorganic phosphorus. The second half of the extract was used for analysis of the fatty acid content of phosphatidylcholine by conversion of methyl esters. Details of these methods have been published elsewhere. ${ }^{8-11}$

The surfactant phospholipid characteristics of the lung washes used for comparison of differences between the groups were: the absolute concentration of the three surfactant phospholipids (phosphatidylcholine, phosphatidylinositol, and phosphatidylglycerol), their concentration with respect to sphingomyelin (phospholipid:sphingomyelin ratio), their relative concentrations, and the relative fatty acid composition of phosphatidylcholine.

ETHICAL ASPECTS

The study had the approval of the local research and ethical committee.

\section{STATISTICAL METHODS}

Statistical evahuation was undertaken using nonparametric methods ( $\chi^{2}$ with Yates's correction for comparison of frequencies and MannWhitney U or Kruskal-Wallis for comparison of medians).
Table 1 Age at death and death-postmortem interval

\begin{tabular}{llll}
\hline $\begin{array}{l}\text { Clinicopathological } \\
\text { diagnosis }\end{array}$ & No of infants & $\begin{array}{l}\text { Median (range) } \\
\text { age (weeks) }\end{array}$ & $\begin{array}{l}\text { Median (range) } \\
\text { death-postmortem } \\
\text { interval (hours) }\end{array}$ \\
\hline SIDS & 23 & $12(3-21)$ & $30(5-72)$ \\
SIDS plus & 12 & $18(5-35)$ & $8(6-76)$ \\
Non-SIDS & 11 & $31(4-100)^{*}$ & $22(6-34)$ \\
\hline
\end{tabular}

${ }^{*} \mathrm{p}<0 \cdot 0005$.

\section{Results}

Of the 46 infants studied, 23 had a clinicopathological diagnosis of 'SIDS alone', 12 had a diagnosis of 'SIDS plus', and 11 were classified as 'non-SIDS'. The associated findings in the 12 cases of SIDS plus were: tracheobronchitis $(n=4)$, bronchitis $(n=2)$, bronchopulmonary dysplasia $(n=2)$, influenza, bronchiolitis, pneumonia, and a history of recent upper respiratory infection (one case of each). The causes of death in the 11 cases of non-SIDS were: congenital heart disease $(n=5)$, intussusception, asphyxia, head injury, congenital neurofibromatosis, gastric rupture, and haemophilus meningitis (one case of each).

The median age at death and median deathpostmortem interval are shown in table 1 . In many cases, especially those in the two SIDS groups the precise time of death was not known. Where this applied an estimate of the time of death was calculated as the mean point between when the baby was last seen alive and when the baby was found dead. There were no significant differences between the three groups in terms of death-postmortem interval; however, the non-SIDS infants were significantly older than those infants dying from SIDS and SIDS plus $(\mathrm{p}<0.0005)$.

COMPARISON OF LEFT AND RIGHT LUNGS

For each surfactant variable (concentrations and relative percent of phosphatidylcholine, phosphatidylinositol, and phosphatidylglycerol, their ratio with respect to sphingomyelin, and the relative fatty acid content of phosphatidylcholine) the data from the 46 left lung washings were compared with those from the 46 right lung washings. There were no significant differences for all 10 variables between the left and right lungs. Therefore in all subsequent analyses we used the mean values of left and right lung washings for each case.

CLINICOPATHOLOGICAL DIAGNOSIS (TABLE 2) The lung washings from babies with SIDS and SIDS plus had significantly lower concentrations of phosphatidylcholine (concentration, ratio to sphingomyelin, and relative percent) and a lower palmitic acid content in phosphatidylcholine compared with the lung washings from

Table 2 Surfactant phospholipids and clinicopathological diagnosis

\begin{tabular}{|c|c|c|c|}
\hline $\begin{array}{l}\text { Surfactant phospholipid } \\
\text { characteristic }\end{array}$ & $\underset{(n=23)}{S I D S}$ & $\underset{(n=12)}{\operatorname{SIDS} \text { plus }}$ & $\begin{array}{l}\text { Non-SIDS } \\
(n=11)\end{array}$ \\
\hline $\begin{array}{l}\text { (a) Median (range) concentration }(\mu \mathrm{g} / \mathrm{ml}) \\
\text { Phosphatidylcholine } \\
\text { Phosphatidylinositol } \\
\text { Phosphatidylglycerol }\end{array}$ & $\begin{array}{c}63 \cdot 1(17 \cdot 9-193 \cdot 9) \\
7 \cdot 1(0 \cdot 7-26 \cdot 0) \\
9 \cdot 3(1 \cdot 3-27 \cdot 9)\end{array}$ & $\begin{array}{c}65 \cdot 8(13 \cdot 6-117 \cdot 1) \\
8 \cdot 5(1 \cdot 3-15 \cdot 5) \\
6 \cdot 2(2 \cdot 8-19 \cdot 0)\end{array}$ & $\begin{array}{c}141 \cdot 2(58 \cdot 3-219 \cdot 1)^{*} \\
7 \cdot 4(2 \cdot 0-18 \cdot 6) \\
12 \cdot 3(2 \cdot 1-23 \cdot 7)\end{array}$ \\
\hline $\begin{array}{l}\text { (b) Median (range) ratio to sphingomyelin } \\
\text { Phosphatidylcholine } \\
\text { Phosphatidylinositol } \\
\text { Phosphatidylglycerol }\end{array}$ & $\begin{array}{l}3.96(1.69-11.05) \\
0.52(0.09-2.22) \\
0.59(0.04-1.27)\end{array}$ & $\begin{array}{l}3.05(2.57-10.33) \\
0.54(0.07-1.5) \\
0.49(0.16-0.96)\end{array}$ & $\begin{array}{c}10.05(3.04-19 \cdot 45)^{*} \\
0.87(0.18-1.49) \\
0.77(0.18-3.81)\end{array}$ \\
\hline $\begin{array}{l}\text { (c) Median (range) relative percent } \\
\text { Phosphatidylcholine } \\
\text { Phosphatidylinositol } \\
\text { Phosphatidylglycerol }\end{array}$ & $\begin{array}{c}46 \cdot 3(29 \cdot 1-65 \cdot 4) \\
6 \cdot 2(0 \cdot 5-15 \cdot 9) \\
5 \cdot 3(1 \cdot 9-18 \cdot 1)\end{array}$ & $\begin{aligned} 44 \cdot 2 & (20 \cdot 6-61 \cdot 9) \\
6 \cdot 2 & (2 \cdot 0-9 \cdot 4) \\
6 \cdot 3 & (1 \cdot 4-11 \cdot 4)\end{aligned}$ & $\begin{array}{c}63 \cdot 8(33 \cdot 4-71 \cdot 8)^{* *} \\
5 \cdot 2(1 \cdot 0-15 \cdot 1) \\
4 \cdot 4(1 \cdot 6-8 \cdot 6)\end{array}$ \\
\hline $\begin{array}{l}\text { (d) Median (range) relative percent } \\
\text { methyl palmitate in phosphatidylcholine }\end{array}$ & $44 \cdot 8(15 \cdot 2-56 \cdot 8)$ & $46 \cdot 3(36 \cdot 5-57 \cdot 0)$ & $57 \cdot 0(43 \cdot 1-64 \cdot 8)^{* * *}$ \\
\hline
\end{tabular}


Table 3 Surfactant phospholipids and the presence of recognised pathogens

\begin{tabular}{|c|c|c|}
\hline $\begin{array}{l}\text { Surfactant phospholipid } \\
\text { characteristic }\end{array}$ & $\begin{array}{l}\text { Pathogen } \\
\text { positive }(n=10)\end{array}$ & $\begin{array}{l}\text { Pathogen } \\
\text { negative }(n=36)\end{array}$ \\
\hline $\begin{array}{l}\text { (a) Median (range) concentration }(\mu \mathrm{g} / \mathrm{ml}) \\
\text { Phosphatidylcholine } \\
\text { Phosphatidylinositol } \\
\text { Phosphatidylglycerol }\end{array}$ & $\begin{array}{c}148 \cdot 9(58 \cdot 1-219 \cdot 1) \\
11 \cdot 4(2 \cdot 0-18 \cdot 6) \\
13 \cdot 4(6 \cdot 3-23 \cdot 7)\end{array}$ & $\begin{array}{c}64 \cdot 6(13 \cdot 6-154 \cdot 5) \\
7 \cdot 1(0 \cdot 7-26 \cdot 0) \\
7 \cdot 0(1 \cdot 3-21 \cdot 9)^{*}\end{array}$ \\
\hline $\begin{array}{l}\text { (b) Median (range) ratio to sphingomyelin } \\
\text { Phosphatidylcholine } \\
\text { Phosphatidylinositol } \\
\text { Phosphatidylglycerol }\end{array}$ & $\begin{array}{l}8.26(2.78-19 \cdot 45) \\
0.67(0.18-1.82) \\
0.89(1.69-12.63)\end{array}$ & $\begin{array}{l}3.70(1.69-12.63)^{k} \\
0.59(0.04-3.81) \\
0.52(0.07-2 \cdot 22)\end{array}$ \\
\hline
\end{tabular}

Table 4 Surfactant phospholipids and the presence of organisms with reported phospholipase A2 activity $^{12}$

\begin{tabular}{|c|c|c|}
\hline $\begin{array}{l}\text { Surfactant phospholipid } \\
\text { characteristic }\end{array}$ & $\begin{array}{l}\text { Organisms with } \\
\text { reported phospholipase } \\
\text { A2 activity }\end{array}$ & $\begin{array}{l}\text { No organisms with } \\
\text { reported phospholipase } \\
\text { A2 activity }\end{array}$ \\
\hline $\begin{array}{l}\text { No of cases an } \\
\text { (a) Median (range) concentration }(\mu \mathrm{g} / \mathrm{ml}) \\
\text { Phosphatidylcholine } \\
\text { Phosphatidylinositol } \\
\text { Phosphatidylglycerol }\end{array}$ & $\begin{array}{l}d \text { SIDS plus cases } \\
30 \\
64 \cdot 2(22 \cdot 0-196 \cdot 6) \\
5 \cdot 7(0-20 \cdot 4) \\
4 \cdot 9(0-21 \cdot 0)\end{array}$ & $\begin{array}{l}5 \\
80 \cdot 5(21 \cdot 5-138 \cdot 5) \\
8 \cdot 7(1 \cdot 4-15 \cdot 2) \\
18 \cdot 2(0 \cdot 3-24 \cdot 7)^{*: *}\end{array}$ \\
\hline $\begin{array}{l}\text { (b) Median (range) relative percent } \\
\text { methyl palmitate in phosphatidylcholine }\end{array}$ & $47 \cdot 3(15 \cdot 3-57 \cdot 0)$ & $49 \cdot 6(36 \cdot 6-55 \cdot 0)$ \\
\hline $\begin{array}{l}\text { No of cases } \\
\text { (a) Median (range) concentration }(\mu \mathrm{g} / \mathrm{ml}) \\
\text { Phosphatidylcholine } \\
\text { Phosphatidylinositol } \\
\text { Phosphatidylglycerol }\end{array}$ & $\begin{array}{l}6 \\
6 \\
22 \cdot 0(24 \cdot 0-113 \cdot 2) \\
6 \cdot 8(0-9 \cdot 6) \\
2 \cdot 0(0-16 \cdot 3)\end{array}$ & $\begin{array}{l}5 \\
213 \cdot 86(138 \cdot 5-223 \cdot 86) \\
17 \cdot 8(1 \cdot 7-36 \cdot 6) \\
17 \cdot 6 \quad(10 \cdot 4-25 \cdot 0)\end{array}$ \\
\hline $\begin{array}{l}\text { (b) Median (range) relative percent } \\
\text { methyl palmitate in phosphatidylcholine }\end{array}$ & $41 \cdot 1(23 \cdot 1-46 \cdot 2)$ & $57 \cdot 8(49 \cdot 7-57 \cdot 8)^{\text {***:**: }}$ \\
\hline
\end{tabular}

babies with non-SIDS. There were, however, no significant differences in the phosphatidylinositol and phosphatidylglycerol content of the groups (table 2).

PRESENCE OF KNOWN PATHOGENS (TABLE 3)

Six infants in the SIDS groups and four infants in the non-SIDS group had recognised pathogens present on microbiological examination: they were Haemophilus influenzae $(\mathrm{n}=3)$, respiratory syncytial virus $(n=3)$, Streptococcus pneumoniae, Streptococcus pyogenes, influenza virus type $A$, and adenovirus type 2 (one case of each).

The pathogen positive group $(n=10)$ had significantly higher concentrations of phosphatidylcholine and phosphatidylglycerol and ratios of phosphatidylcholine and phosphatidylglycerol to sphingomyelin than the pathogen negative group $(n=36)$ (table 3$)$. There were no other significant differences in surfactant phospholipid characteristics between the two groups.

PRESENCE OF ORGANISMS WITH REPORTED PHOSPHOLIPASE A2 ACTIVITY (TABLE 4)

Organisms isolated in the study with reported phospholipase A2 activity were: Staphylococcus albus, $S$ pneumoniae, Escherichia coli, Streptococcus faecalis, and Streptococcus viridans. ${ }^{12}$

There were 36 cases where organisms were identified with reported phospholipase A2 activity. Thirty of these were from the SIDS groups, whereas, only six were from the nonSIDS group. The remaining 10 cases did not have any organisms with reported phospholipase
A2 activity (five SIDS or SIDS plus and five non-SIDS). However, this association of phospholipase A2 activity with the SIDS groups is not significant.

Because of this association of organisms with phospholipase A2 activity with the SIDS groups we analysed the phospholipid characteristics of SIDS and non-SIDS groups separately. All surfactant phospholipid characteristics were higher in the cases where no organisms with phospholipase A2 activity were found for both SIDS and non-SIDS groups. Only median concentrations of phosphatidylcholine, phosphatidylinositol, and phosphatidylglycerol and the relative percent methyl palmitate in phosphatidylcholine are illustrated in table 4 for clarity.

The differences reached significance for phosphatidylglycerol concentration in the SIDS groups $(\mathrm{p}<0.05)$ and phosphatidylcholine concentration, phosphatidylcholine:sphingomyelin ratio, and relative percent phosphatidylcholine $(\mathrm{p}<0.05)$, and methyl palmitate content of phosphatidylcholine in the non-SIDS groups $(\mathrm{p}<0.001)$. However, there were no differences in lysophosphatidylcholine concentrations between phospholipase A2 positive and negative cases in both SIDS and non-SIDS groups.

HISTOLOGICAL EVIDENCE OF INFLAMMATION OR OTHER ABNORMALITY IN THE RESPIRATORY TRACT Twenty infants in the SIDS groups and five infants in the non-SIDS group had histological evidence of inflammation or other abnormality in the respiratory tract. The pathological conditions recorded were: mild lymphocytic tracheitis $(n=5)$, tracheobronchitis with appreciable lymphocytic infiltrate $(n=5)$, mild pulmonary inflammation and oedema $(n=5)$, bronchiolitis $(n=4)$, mild pulmonary lymphocytic infiltration $(n=3)$, definite pneumonia $(n=2)$, and bronchopulmonary dysplasia $(\mathbf{n}=1)$.

There were no significant differences in any of the surfactant phospholipid variables between those infants with histological evidence of inflammation and those without.

\section{ASPIRATION OF STOMACH CONTENTS}

Four infants in the SIDS groups and one infant in the non-SIDS group had evidence of aspirated gastric contents at postmortem examination.

There were no significant differences in any of the surfactant phospholipid variables between those infants with evidence of aspiration and those who did not.

\section{AGE AT DEATH}

In the SIDS groups, 19 infants died between 2 and 14 weeks and 16 died after 14 weeks. In the non-SIDS group only three infants died beţween 2 and 14 weeks and eight died after 14 weeks. Because of this highly significant difference in age distribution between the SIDS and nonSIDS groups (table 1), the association between age at death and surfactant abnormality was studied separately for the SIDS and non-SIDS infants. 
There were no significant differences in any of the surfactant phospholipid variables within both the SIDS and non-SIDS groups between those infants dying between 2 and 14 weeks and those dying after 14 weeks.

\section{INFANT'S SEX}

There were equal numbers of boys and girls in the study. The boy:girl distribution by SIDS and non-SIDS groups were 17:18 and 6:5 respectively.

There were no significant differences in any of the surfactant phospholipid variables between the boys and the girls.

\section{DEATH-POSTMORTEM INTERVAL}

The precise time of death was not known in many cases, especially those in the two SIDS groups. Nevertheless it was possible to identify in every case whether the postmortem examination was performed within 24 hours of the death or after a longer interval.

Twenty two infants had the postmortem examination performed within 24 hours of the death (SIDS:non-SIDS ratio=16:6), and 24 had it performed at least 24 hours after the death (SIDS:non-SIDS ratio=19:5).

There were no significant differences in any of the surfactant phospholipid variables between those infants who had an early postmortem examination and those where it was delayed by at least 24 hours.

\section{Discussion}

This is the fourth published report of a prospective study demonstrating an association between SIDS and surfactant abnormality, ${ }^{3-5}$ the first report being a retrospective chance finding. ${ }^{2}$ All the prospective studies including this study have encountered the same difficulty in identifying a 'control' group that was comparable with the SIDS group in age at death (table 1). In this study, however, we have shown that the phospholipid characteristics of those infants dying between 2 and 14 weeks were no different from those dying after 14 weeks. Thus age at death is unlikely to be a significant factor in explaining the findings. Thus the association seems to be real; however, the two key questions are, firstly, whether the abnormality could be involved in the pathogenesis of SIDS and, secondly, whether it is a primary or secondary phenomenon?

How might such surfactant abnormalities contribute to the death of a baby from SIDS? Talbert and Southall have postulated that defective surfactant in early infancy when small alveoli are being formed could lead to atelectasis and sudden profound hypoxia. ${ }^{13}$ Such episodes could be rapidly terminated by inspiratory effort and go unnoticed unless the child failed to respond. ${ }^{14} 15$ Postmortem examination of the lungs in sudden death infants does not usually reveal extensive pulmonary atelectasis, however, ${ }^{16}$ and studies of lung washings from infants dying from SIDS have demonstrated normal pressure-volume relationships. ${ }^{6}$ Of course, it may be that atelectasis is not the pathological manifestation of surfactant abnormality in such babies.

Apart from stabilising alveolar membranes, especially in end expiration, surfactant plays a part in clearing lung fluid. ${ }^{8}$ Indeed, surfactant abnormality can be manifest in a number of clinical settings associated with pulmonary oedema such as transient tachypnoea of the newborn ${ }^{11}$ and certain adult respiratory disorders. ${ }^{17}$ Pulmonary oedema is a common postmortem finding in SIDS cases, ${ }^{16}$ and it may be that the surfactant abnormality is responsible for this. An abnormality of surfactant at a time of less stable respiratory control in the developing infant ${ }^{18}$ could possibly result in the rapid development of pulmonary oedema, significant hypoventilation, and apnoea.

If the surfactant abnormality that we and other groups have described in SIDS victims were present as a primary developmental problem, it seems likely that some difference in respiratory pattern might be identifiable in such infants. Such differences were not demonstrated, however, by various analyses of respiratory patterns recorded in the first week and at 6 weeks in 29 infants who subsequently died of SIDS when compared with matched controls. ${ }^{19-21}$ The argument against a primary phenomenon is further strengthened by certain inconsistencies in the phospholipid findings in the reported studies. Babies with known primary surfactant deficiency disease (respiratory distress syndrome) have consistently lower concentrations of all three surfactant phospholipids ${ }^{11}$; however, we have found only abnormalities in phosphatidylcholine in our study with no changes in phosphatidylinositol and phosphatidylglycerol values. Similarly in other reports all three phospholipids have never been demonstrated to be reduced in SIDS infants in the same study. Furthermore, while some studies have shown reductions not only in phosphatidylcholine but in phosphatidylinositol or phosphatidylglycerol also, others have failed to demonstrate altered phosphatidylcholine values while phosphatidylinositol and phosphatidylglycerol contents were reduced. ${ }^{2-5}$

If a secondary/acquired deficiency of surfactant were contributing to death it must occur relatively late or suddenly in the process as a recent study has shown no greater incidence of respiratory symptoms or signs in babies 24 hours before death from SIDS compared with age matched controls in the same neighbourhood. ${ }^{22}$

Yet if the association of surfactant abnormality and SIDS is secondary - to what is it secondary? We have failed to demonstrate that the association is secondary to infant sex, death-postmortem interval, age at death (see above), aspiration of stomach contents, and the presence of inflammation in the respiratory tract. Indeed, when the data were analysed according to the presence of recognised pathogens in the respiratory tract then significantly higher concentrations of phosphatidylcholine and phosphatidylglycerol were found.

The only possible secondary explanation we could find for the association of SIDS and 
surfactant abnormality was that those infants found to have organisms in their respiratory tract with reported phospholipase A2 activity ${ }^{12}$ also had similar alterations in surfactant phospholipid characteristics as found in the infants with SIDS. Admittedly, this speculation might be considered to be contrived. Surfactant is normally produced and turned over fast enough to cope with local degradation. Furthermore, if phospholipase was causing such a large abnormality, lysophosphatidylcholine values in both those infants with SIDS and surfactant abnormality and those infants with phospholipase A2 positive organisms might be expected to be raised, but this was not the case. This hypothesis, however, should be tested prospectively. It has recently been demonstrated that eight of 29 babies (28\%) dying from SIDS had organisms isolated from their lungs with significant in vitro phospholipase $\mathrm{A} 2$ activity. ${ }^{23}$

We are very grateful to the following for financial support: the University of Bristol, the Foundation for the Study of Infant Deaths, Birthright, Southmead Hospital Research Foundation, and South Western Regional Health Authority.

1 Milner AD. Recent theories on the cause of cot death. $\mathrm{Br}$ Med f 1987;295:1366-8.

2 Morley CJ, Hill CM, Brown BD, Barson AJ, Davis JA. Surfactant abnormalities in babies dying from the sudden infant death syndrome. Lancet 1982;i:1320-2.

3 Gibson RA, McMurchie EJ. Changes in lung surfactant lipids associated with the sudden infant death syndrome. Aust Paediatr 7 1986;22(suppl 1):77-80.

4 Hill CM, Brown BD, Morley CJ, Davis JA, Barson AJ. Pulmonary surfactant. II. In sudden infant death syndrome. Early Hum Dev 1988;16:153-62.

5 Gibson RA, McMurchie EJ. Decreased lung surfactant disaturated phosphatidylcholine in sudden infant death disaturated phosphatidylcholine in sudden

6 Fagan DG, Milner AD. Pressure volume characteristics of the lungs in the sudden infant death syndrome. Arch Dis Child 1985;60:471-3.
7 Folch J, Lees M, Sloane-Stanley, GH. A simple method for the isolation and purification of total lipids from animal the isolation and purification of total
tissues. $\mathcal{F}$ Biol Chem 1957;226:497-509.

8 James DK. Fetal surfactant maturation and neonatal respiratory disorders. Cambridge: University of Cambridge, 1984. (MD thesis.)

9 James DK, Harkes A, Williams M, Chiswick ML, Tindall VR. Amniotic fluid phosphatidylglycerol and prediction of fetal lung maturity in diabetic pregnancies. Fournal of Obstetrics and Gynaecology 1984;4:166-9.

10 James DK, Chiswick ML, Harkes A, Williams M, Tindal VR. Maternal diabetes and neonatal respiratory distress. I. Maturation of fetal surfactant. Br $\mathcal{f}$ Obstet Gynaecol 1984;91:316-24.

11 James DK, Chiswick ML, Harkes A, Williams M, Hallworth $\mathrm{J}$. Non-specificity of surfactant deficiency in neonatal respiratory disorders. $\mathrm{Br} M e d$ f 1984;288:1635-8.

12 Bejar R, Curbelo V, Davis C, Gluck L. Premature labor. II. Bacterial sources of phospholipase. Obstet Gynecol 1981;57: 479-82.

13 Talbert DG, Southall DP. A bimodal form of alveolar behaviour produced by a defect in lung surfactant-a possible mechanism for sudden infant death syndrome. possible mechanism

14 Morley CJ, Davies RJ, Hill CM, Heath ME. Alveoli and abnormal surfactant. Lancet 1985 ;i:1329-30.

15 Southall DP, Talbert DG. Sudden atelectasis apnoea braking syndrome. In: Hollinger MA, ed. Current topics in pulmonary pharmacology and toxicology. Vol 3. New York: Elsevier, 1987, 210-81.

16 Berry PJ, Keeling JW. The investigation of sudden unexpected death in infancy. Recent Advances in Histopathology 1989;14:251-79.

17 Shelley SA. Biochemical composition of adult human lung surfactant. Lung 1982;160:195-206.

18 Fleming PJ, Goncalves HL, Levine MR, Woolard S. The development of stability of respiration in human infants: changes in ventilation responses to spontaneous sighs. changes in ventilation responses

19 Southall DP, Richards JM, De Swiet M. Identification of infants destined to die unexpectedly during infancy: infants destined to die unexpectedly during infancy: evaluation of predictive importance of prolonged apnoea
and disorders of cardiac rhythm or conduction. $\mathrm{Br} \mathrm{Med} \mathcal{J}$ and disorders of

20 Fleming PJ, Levine MR, Long AM, Cleeve J. The maturation of the control of respiration in infancy. In: Walters DV, Strang LB, Genbelle F, eds. Physiology of the fetal and neonatal lung. Lancaster: M T P Press, 1986.

21 Southall DP. Role of apnoea in the sudden infant death syndrome: a personal view. Pediatrics 1988;81:73-84.

22 Gilbert R, Fleming PJ, Rudd P, Berry PJ. Clinical features in the 24 hours prior to sudden unexplained infant death. Early Hum Dev (in press).

23 Adams HE. Phosphatidylcholine degration by bacteria isolated from the lungs of sudden infant death syndrome cases. Guildford: University of Surrey, 1989. (MSc thesis.) 